\title{
Clinical Management of Pediatric Acute-Onset Neuropsychiatric Syndrome: Part III-Treatment and Prevention of Infections
}

\author{
Michael S. Cooperstock, MD, MPH, Susan E. Swedo, MD, \\ Mark S. Pasternack, MD, and Tanya K. Murphy, $\mathrm{MD}^{4}$; for the PANS/PANDAS Consortium
}

\begin{abstract}
Objectives: Pediatric acute-onset neuropsychiatric syndrome (PANS) and its subset, pediatric autoimmune neuropsychiatric disorder associated with streptococcal infection (PANDAS), are emerging autoimmune encephalopathies of childhood. Management guidelines are needed. This article, from the PANS/PANDAS Consortium, presents a consensus management guideline for the infection components. Accompanying papers from the Consortium discuss psychiatric and immunomodulatory management.

Methods: Literature was reviewed and integrated with the clinical experience of the authors to provide a set of practical guidelines. This article was submitted to all members of the PANS/PANDAS Consortium, and their additional comments were added.

Results: The relationships between PANS and infections are reviewed. An approach to the retrospective diagnosis of group A streptococcal infection for an operational definition of PANDAS is proposed. An initial course of anti-streptococcal treatment is proposed for all newly diagnosed PANS cases. Chronic secondary antimicrobial prophylaxis is suggested for children with PANDAS who have severe neuropsychiatric symptoms or recurrent group A Streptococcus-associated exacerbations. Guidelines for children with non-streptococcal PANS include vigilance for streptococcal pharyngitis or dermatitis in the patient and close contacts. All patients with PANS or PANDAS should also be closely monitored for other intercurrent infections, including sinusitis and influenza. Intercurrent infections should be diagnosed and treated promptly according to current standard guidelines. A guideline for the assessment of infection at initial onset or during neuropsychiatric exacerbations is also presented. Standard immunizations and attention to vitamin D are encouraged. Data indicating limited utility of adenotonsillectomy and probiotics are presented.

Conclusion: A working guideline for the management of infection issues in PANS and PANDAS, based on literature and expert opinion, is provided.
\end{abstract}

Keywords: pediatric acute-onset neuropsychiatric syndrome, pediatric autoimmune neuropsychiatric syndrome associated with streptococcal infection, PANS, PANDAS

\section{Introduction}

$\mathbf{P}$ EDiatric Acute-onset Neuropsychiatric Syndrome (PANS) is an emerging autoimmune encephalopathy of childhood (Swedo et al. 1998, 2012). Its defining symptoms include a notably abrupt onset of obsessive-compulsive disorder (OCD) or eating restriction accompanied by two or more additional features. These may include psychiatric symptoms such as anxiety (typically including separation anxiety), attention deficit, hyperkinesis, emotional lability and/or depression, irritability, aggressiveness or oppositional behavior, and academic decline. Associated neurologic findings are often present. These include cognitive impairments, motor or vocal tics, increased sensory sensitivities, choreiform finger movements, deteriorating penmanship, and urinary frequency and/or enuresis. Sleep disruptions are also characteristic. The definitive diagnosis also includes a relapsing-remitting course. The long-term course has yet to be definitively described. The majority of children under treatment show overall improvement over months to years. Relapses may still occur after long periods of remission.

\footnotetext{
${ }^{1}$ Division of Infectious Diseases, University of Missouri School of Medicine, Columbia, Missouri.

${ }^{2}$ Department of Pediatrics and Developmental Neuroscience Branch, National Institute of Mental Health (NIMH), Rockville, Maryland.

${ }^{3}$ Department of Pediatric Infectious Disease, Massachusetts General Hospital, Boston, Massachusetts.

${ }^{4}$ Director and Professor of Pediatric Neuropsychiatry, Pediatrics and Psychiatry, University of South Florida, St. Petersburg, Florida.
}

(c) Michael S. Cooperstock et al., 2017; Published by Mary Ann Liebert, Inc. This article is available under the Creative Commons License CC-BY-NC (http://creativecommons.org/licenses/by-nc/4.0). This license permits non-commercial use, distribution and reproduction in any medium, provided the original work is properly cited. Permission only needs to be obtained for commercial use and can be done via RightsLink. 
Guidelines for diagnostic assessment of PANS and pediatric autoimmune neuropsychiatric disorder associated with streptococcal infection (PANDAS) have been developed by the PANS Research Consortium (Chang et al. 2015). Clinical experience of the Consortium, together with available empiric data, provides support for a set of practice-based guidelines for patient management. This article provides a practical approach to the management of infection. Accompanying papers address neuropsychiatric (Thienemann et al. 2017) and immunomodulatory (Frankovich et al. 2017) interventions.

\section{Infections in PANS}

\section{Inciting infections}

PANS and PANDAS are closely associated with infections. Both the initial onset and subsequent exacerbations are usually incited by a variety of recognizable infections (Swedo et al. 1998; Murphy et al. 2004, 2015; Frankovich et al. 2015); alternatively, these conditions may be associated with life stresses (Lin et al. 2010), whereas in other cases there is no clear inciting factor. Although the primary focus has been on streptococcal infections, a variety of inciting infections have been observed. The most common infection sites are in the upper respiratory tract, including rhinitis, sinusitis, and pharyngitis. The specific microbe most commonly recognized has been group A Streptococcus (GAS). As noted later, Mycoplasma pneumoniae, as well as influenza and other common viruses have also been noted, although they are not as well described. The variety and relative frequency of non-streptococcal triggers of onset and exacerbation strongly suggests that nonspecific immune activation mechanisms may also contribute importantly to symptom development.

\section{Evidence for an association between GAS and PANDAS}

Clinical association. A proposed subset of PANS are those cases that are associated with GAS infection, either at initial onset of the neuropsychiatric symptoms or at an exacerbation. This subset, which constitutes a substantial fraction of PANS cases, is termed PANDAS. Retrospective evidence for an inciting GAS infection in PANS (i.e., the PANDAS subset) has been found in as many as 40\%-77\% of cases (Swedo et al. 1998; Murphy et al. 2004, 2015; Frankovich et al. 2015). A prospective study of established cases identified titer rises in the GAS-specific antibodies antistreptolysin O (ASO), anti-DNAse B (ADB), or streptococcal carbohydrate (anti-CHO) in $43 \%$ and $44 \%$ of defined OCD or tic exacerbations, respectively (Murphy et al. 2004). Not all GAS infections, however, induced exacerbations (Murphy et al. 2004). In this and a subsequent study, elevated or rising streptococcal antibody titers were associated with the relapsing-remitting course characteristic of PANDAS (Murphy et al. 2004, 2012).

A particularly informative prospective, primary-care based study noted that 11 of 12 PANDAS cases $(92 \%)$ had previous GAS pharyngitis documented 1-7 times before the inciting episode. The initiating infections demonstrated definite pharyngeal erythema but was otherwise notably mild: usually afebrile, with minimal exudate and cervical lymphadenopathy (Murphy and Pichichero 2002).

Importantly, the relationship between GAS and PANDAS is further strengthened among those with a history of prior GAS infections. Cases with multiple prior GAS infections have been found to have more frequent relapses (Swedo et al. 1998; Mell et al. 2005; Murphy et al. 2007, 2012; Murphy et al. 2015). Further, the rela- tionship appears to be quantitative, with the number of prior GAS infections being correlated with the frequency and severity of relapses (Murphy and Pichichero 2002).

Epidemiologic studies. Population-based epidemiologic studies provide additional support for an association between GAS and PANDAS-like neuropsychiatric syndromes. One such study showed an association of OCD, tic disorder, and/or Tourette syndrome with streptococcal infection in the previous 3 months, with an odds ratio of 2.2 (Mell et al. 2005). A similar population-based study (Leslie et al. 2008) demonstrated an association between neuropsychiatric symptoms and GAS infection in the previous year (odds ratio 1.54), although not in the previous 3 months.

Prospective study of GAS acquisition. An important prospective school-based study evaluated the effects of acquired asymptomatic pharyngeal GAS colonization over 8 months in a population of 693 typical elementary schoolchildren. The study showed a striking increase in neurologic and behavioral symptoms associated with GAS acquisition (Murphy et al. 2007). This is noteworthy given the high point prevalence of childhood GAS colonization, ranging 3\%-26\% in various settings (Shaikh et al. 2010). It is also noteworthy that a similar phenomenon was not observed on follow-up of 411 children with promptly treated acute GAS pharyngitis in a prospective primary-care setting (Perrin et al. 2004).

A degree of confusion has arisen since two additional prospective studies seemed to show little relationship between GAS infections and exacerbations of proposed PANDAS cases (Kurlan et al. 2008; Leckman et al. 2011). However, these patients may have represented a distinctive population (Luo et al. 2004; Kurlan et al. 2008; Leckman et al. 2011; Martino et al. 2011; discussed in Murphy et al. 2014).

Molecular mimicry between GAS and neural antigens. Sera from children with PANDAS contain group A streptococcal carbohydrate-specific antibodies whose cognate antigens are mimetic with neural antigens, including human neuronal dopamine receptors 1 and 2, lysoganglioside, and/or tubulin. These sera also frequently show autoantibody-mediated functional activation of a human neural cell line in vitro (Kirvan et al. 2003; Cox et al. 2015; Cunningham and Cox 2016). A monoclonal antibody derived from a patient with Sydenham's chorea has been used to demonstrate cross-reactive molecular mimicry between the GAS polysaccharide and each of the human neuronal reactions listed earlier that are known to be important for patients with PANDAS as well as for those with Sydenham's chorea (Kirvan et al. 2006a,b; Kirvan et al. 2007; Cox et al. 2013; Cunningham and Cox 2016). Each of these cross-reactions can be blocked by N-acetyl- $\beta$-dglucosamine, which, thus, appears to be a key epitope for GAS polysaccharide cross-reactivity.

Animal models. Three animal models have been utilized to demonstrate autoantibody-mediated neuropsychiatric changes after crude GAS immunization of mice or rats (Hoffman et al. 2004; Brimberg et al. 2012), after passive transfer of IgG intravenously from GAS-immunized mice (Yaddanapudi et al. 2010), or after transfer of IgG into the striatum of naïve rats (Lotan et al. 2014). In a recent fourth animal model, it was demonstrated that repeated nasopharyngeal GAS infections resulted in trans-olfactory sterile central nervous system inflammation mediated by Th17 lymphocytes (Dileepan et al. 2016). 


\section{PANDAS natural history}

Latent period. The latent period between GAS infection and the onset of PANDAS has not been fully clarified. The onset of PANDAS cases reported by Murphy and Pichichero (2002) was concurrent with GAS infection. Our observations (unpublished) suggest that OCD may begin as early as 1-3 days before the onset of GAS pharyngeal symptoms, and as late as 30 days or more after the GAS infection. The more prolonged post-streptococcal latency period observed for Sydenham's chorea (Eshel et al. 1993) seems to be rare for PANDAS exacerbations, but it may explain difficulties in documenting GAS infections at initial symptom onset.

Asymptomatic GAS acquisition. It is also likely that PANDAS may follow asymptomatic acquisition of pharyngeal GAS. Asymptomatic acquisition can generate ASO and ADB immune responses (Johnson et al. 2010), and it is capable of generating rheumatic fever recurrences (Gerber et al. 2009), as well as the neurologic symptoms described in the school-based study discussed earlier (Murphy et al. 2007). Asymptomatic pharyngeal GAS may be found in children presenting with PANS/PANDAS symptoms. This may be etiologically relevant, especially if rising GAS antibody titers are demonstrated.

\section{Acute GAS Infection}

\section{GAS pharyngitis}

GAS pharyngitis characteristically presents with the acute onset of sore throat, dysphagia, pharyngeal erythema with or without exudates, fever, and tender anterior cervical lymphadenopathy in the absence of cough or nasal congestion. It should be noted that a report of sore throat over the trachea or larynx, rather than the pharynx or cervical nodes, is not characteristic of GAS infection. In younger children, abdominal pain may be a prominent symptom.

The presence of palatal petechiae or scarlatinaform rash in children with pharyngitis is reported to be $95 \%$ and $98 \%$ specific, respectively, for the diagnosis of GAS (Shaikh et al. 2012). A diagnostic throat swab for streptococcal rapid testing or culture is generally required for diagnosis, however, because no clinical syndrome is considered sufficiently specific for a clinical diagnosis (Shulman et al. 2012). A properly performed throat swab requires a vigorous swipe that includes both tonsils and the posterior pharynx. If a rapid GAS screen is negative, the specimen should be cultured, since about $15 \%$ of GAS pharyngitis is missed by current rapid tests (Lean et al. 2014).

It is important to note that bona fide streptococcal pharyngitis, that is, GAS acquisition with rising serum antibodies, may occur in the absence of clinical symptoms (Johnson et al. 2010).

\section{Other GAS infections}

PANDAS has been described in cases of perianal dermatitis due to GAS (Toufexis et al. 2014). Perianal dermatitis and other GAS perineal infections occur primarily in children who are 2-7 years of age, but they can also occur in older children and adults. These infections are sometimes familial, and they are often associated with pharyngeal acquisition or infection in the patient or a family member. The infection commonly recurs within weeks after a standard course of oral antimicrobial treatment (Clegg et al. 2015). Other extra-pharyngeal GAS infections such as vulvovaginitis, impetigo, or various forms of invasive disease are also suspect, although not as yet reported with PANDAS.

\section{GAS assessment at PANS onset and exacerbations}

Throat swab. A throat swab for GAS is recommended during the initial diagnostic evaluation for PANS, particularly if the child is not already receiving antistreptococcal treatment. Testing for GAS is recommended regardless of the presence of clinical pharyngitis or the severity of neuropsychiatric symptoms at that time. A throat swab should also be performed both during exacerbations of neuropsychiatric symptoms and during episodes of pharyngitis, particularly in children not receiving an appropriate antibiotic, or if adherence to the prophylactic regimen is in doubt. Perineal and other extra-oral sites should be inspected routinely, with cultures obtained from suspected infection sites.

The throat of asymptomatic family members and other intimate contacts should also be swabbed, if possible, at the time of initial diagnosis, and at any time they have pharyngitis symptoms. When patients have PANS exacerbations, untreated close contacts should be questioned about symptoms of pharyngitis or dermatitis, and cultured and treated if positive.

GAS serology. ASO begins to rise at about 1 week and peaks at 3-6 weeks after infection (McCarty 1954; Kaplan et al. 1974); ADB begins to rise at 1-2 weeks and peaks at 6-8 weeks (Ayoub and Wannamaker 1962). These tests are best performed at or near the time of infection and then repeated to demonstrate a serologic rise. It should be noted that even properly timed serial assays have failed to show a rise in as many as $38 \%$ of new pharyngeal GAS acquisitions (Johnson et al. 2010) or in 57\% of children with acute streptococcal pharyngitis (Kaplan et al. 1971).

Single titers have limited utility, since both false positive and false negative values are very common (Johnson et al. 2010). However, as has been noted for rheumatic fever, a single streptococcal antibody may have diagnostic value if elevated at the time of onset (Gerber et al. 2009), although such results must be interpreted with caution (Johnson et al. 2010).

Current enzyme immunoassay or turbidimetric assays for ASO and $\mathrm{ADB}$ give continuous values rather than serial dilution titers. Unfortunately, established standards to define a meaningful antibody rise are not available. Provisionally, we accept a 50\% rise or fall in ASO or ADB as a significant change. This is quantitatively similar to the $0.2 \log _{10}$ change established in earlier studies using serial dilution methods. If prior baseline values are available, it may also be helpful to assay ASO and ADB during neuropsychiatric symptom exacerbations. ASO and ADB levels may also be obtained electively at 3-4 month intervals to assist the clinical recognition of subclinical infection or suboptimal antimicrobial prophylaxis. It is important to utilize a single reliable laboratory for serial testing to maximize dependability of the results.

The Streptozyme test (Wampole Laboratories), a hemagglutinin assay employing red cells coated with five streptococcal antigens, is not recommended pending better standardization (Kaplan and Huew 1980; Kaplan and Kunde 1981; Gerber et al. 2009).

\section{Determination of streptococcal infection for the diagnosis of PANDAS}

The determination of prior GAS infection is often difficult to operationalize in practice for several reasons. Retrospective information is often incomplete or unavailable. In an unknown fraction of cases, GAS identified in a throat culture represents incidental colonization. Conversely, false negative throat swabs may occur due to a faulty technique or an infection sequestered in deep tonsillar core tissue (Saslaw et al. 1962; Gul et al. 2007). An 
immunogenic GAS infection may be clinically overlooked when it is mild or asymptomatic. Properly timed serial ASO and ADB may be unavailable, or falsely negative as noted earlier. Rising streptococcal antibodies frequently cannot be determined, because symptoms have already been present for several weeks at the time of the first evaluation. In such cases, a single set of ASO and ADB levels might be obtained, but should be interpreted with caution, since a positive value may reflect a GAS infection that occurred in the remote past, unrelated to present symptoms, whereas negative titers are obtained in as many as $40 \%$ of GAS infections. (Johnson et al. 2010). Given these uncertainties, it is often difficult to establish "a temporal relationship of GAS to symptom onset or exacerbation" as required for a definitive PANDAS diagnosis. To address this issue, we have found it useful to identify the level of evidence for GAS infection as "adequate" or "not adequate" to justify a working diagnosis of PANDAS, based on available evidence (Table 1).

\section{Management of Streptococcal Infections in PANDAS}

\section{Primary antimicrobial treatment of acute streptococcal infections}

Primary antimicrobial treatment for all patients with pharyngeal GAS is indicated, with oral or intramuscular penicillin as a first choice (Gerber et al. 2009). In current practice, amoxicillin is often used in suspension form for younger children due to its enhanced palatability (American Academy of Pediatrics 2015a). Injectable antibiotic therapy is considered the most reliable, although in practice it is usually reserved for children failing or unable to accept oral therapy. The objective of antimicrobial therapy of acute streptococcal infection is to eradicate the current GAS infection to minimize non-suppurative sequelae such as rheumatic fever (Shulman et al. 2012).

For children allergic to, or intolerant of, penicillin, cephalexin, cefadroxil, clindamycin, azithromycin, or clarithromycin are recommended according to the IDSA 2012 guideline for the treatment of acute GAS pharyngitis (Shulman et al. 2012) (Table 2). Children with persistent or rapidly relapsing pharyngitis may also be treated with these agents, which may be more effective clinically than penicillin or amoxicillin (Casey et al. 2008).

The use of azithromycin as an alternative for the treatment of pharyngeal GAS infection may be less efficacious, due to regional GAS resistance rates as high as $5 \%-10 \%$ or more (Silva-Costa et al. 2015) with an associated potential for the development of sequelae (Logan et al. 2012). Theoretical advantages of azithromycin include its ease of administration, its activity against most Mycoplasma pneumoniae, and its potential immunomodulatory (Obregon et al. 2012) activities. Disadvantages include its potential to promote azithromycin resistance of both GAS and $M$. pneumoniae. The U.S. Food and Drug Administration recommends that it be used with caution in patients with a prolonged QT interval on the electrocardiogram, and may be contraindicated in patients receiving medications that prolong the QT interval, which includes some of the selective serotonin receptor inhibitors (SSRIs), as well as anti-psychotic medications and other psychoactive drugs.

The use of oral clindamycin suspension may be problematic in children due to its unfavorable taste. Recent data suggest that clindamycin resistance may also be emerging, albeit at a lower frequency than azithromycin, in North America and worldwide (Villaseñor-Sierra et al. 2012; O'Dwyer et al. 2013), notably appearing in localized outbreaks of specific GAS emm types (Smit et al. 2015). Also of concern, clindamycin appears to disturb the
Table 1. Provisional Determination of Prior STREPTOCOCCAL INFECTION FOR AN OPERATIONAL DEFINITION OF PANDAS

Adequate for a diagnosis of PANDAS

A rise in serial antibody level, regardless of rapid test or culture result. This definition does not require clinical pharyngitis.

Acute pharyngitis with a positive GAS throat culture, with or without a rising antibody level. ${ }^{\mathrm{a}}$

Pharyngitis with characteristic palatal petechiae. ${ }^{\mathrm{b}}$

Pharyngitis with a characteristic scarlatinaform rash. ${ }^{\mathrm{b}}$

Pharyngitis without a throat swab or serology, but intimate (usually household) exposure to a proven GAS case. ${ }^{\circ}$

Asymptomatic pharyngeal colonization documented after an intimate exposure.

Asymptomatic pharyngeal colonization after a negative throat swab documented within the prior 3-4 months.

Single ASO or ADB antibody level within 6 months after the initial onset of neuropsychiatric symptoms may be accepted as positive if it is $>95$ th percentile, using the laboratory's normal standard for children of comparable age, or provisionally $\mathrm{ASO} \geq 1: 480$ or $\mathrm{ADB} \geq 1: 1280$. $^{\mathrm{d}}$

Both ASO and ADB are elevated at $>80 \%$ percentile for age in the same serum sample within 6 months after the initial onset of neuropsychiatric symptoms. ${ }^{\text {e }}$

Culture-documented streptococcal dermatitis.

Suggestive evidence not adequate for a diagnosis of PANDAS

GAS cultured from a normal-appearing throat, without rising antibody titers. ${ }^{\mathrm{f}}$

Pharyngitis without a swab. ${ }^{\mathrm{g}}$

Either ASO or ADB, but not both, elevated at $>80 \%$ percentile of age norms within 6 months after the initial onset of neuropsychiatric symptoms, and culture negative or unavailable. ${ }^{\mathrm{h}}$

Household exposure to a proven GAS case without clinical pharyngitis or suggestive dermatitis, and without a diagnostic swab.

Intertrigo or perianal dermatitis without confirmatory culture. ${ }^{i}$

${ }^{\mathrm{a}} \mathrm{A}$ large fraction of new asymptomatic GAS acquisitions and acute GAS pharyngitis occurs without a rise in either ASO or anti-DNAse B (see text).

${ }^{\mathrm{b}} \mathrm{A}$ systematic review demonstrated palatal petechiae as $95 \%$ specific, and scarlatina rash as $98 \%$ specific for GAS pharyngitis (Shaikh et al. 2012).

${ }^{c}$ Danchin et al. (2007).

${ }^{\mathrm{d}}$ Upper limit of normal for GAS has conventionally been given at the 80th rather than the 95th percentile to adjust for the high frequency of streptococcal exposure in normal control children. By definition, this standard yields $20 \%$ false positives for a single titer by chance alone. The values given here are twice the 80th percentile values found in a large national study (Kaplan et al. 1998).

${ }^{\mathrm{e}}$ Wannamaker and Ayoub (1960), Kaplan et al. (1998). The 80th percentile upper limit of normal for ASO in the latter study was 1:240, and for ADB it was 1:640.

${ }^{\mathrm{f}}$ The frequency of true carriers vs. bona fide infections in this group is not clear (Johnson et al. 2010).

${ }^{\mathrm{g}}$ Approximately $20 \%-40 \%$ of all childhood pharyngitis is due to GAS (Shaikh et al. 2010; Shulman et al. 2012; Kronman et al. 2014).

${ }^{\mathrm{h}}$ Wannamaker and Ayoub (1960); Johnson et al. (2010).

${ }^{\mathrm{i}}$ Clegg et al. (2015).

ADB, anti-DNAse B; ASO, anti-streptolysin O; PANDAS, pediatric autoimmune neuropsychiatric disorder associated with streptococcal infection; GAS, group A Streptococcus.

protective throat and fecal microbiome to a much greater and a more prolonged degree than other commonly used oral antimicrobial agents (Zaura et al. 2015).

For children allergic or intolerant to the penicillins, the Consortium preference favors cephalexin (bid or tid) or cefadroxil 
Table 2. Antimicrobial Treatment of Acute Streptococcal Pharyngitis

\begin{tabular}{|c|c|c|}
\hline Agent, route, duration & Dose, frequency & Rating $^{\mathrm{a}}$ \\
\hline Penicillin $\mathrm{V}$ po $\times 10$ days & Children: $250 \mathrm{mg} / \mathrm{dose}$ bid or tid; Adolescents or adults: $500 \mathrm{mg} / \mathrm{dose}$ bid & Strong, high \\
\hline Amoxicillin po $\times 10$ days & $50 \mathrm{mg} / \mathrm{kg}$ once daily, maximum $1 \mathrm{~g}$ & Strong, high \\
\hline Benzathine penicillin $\mathrm{G}$ im once & $\leq 27 \mathrm{~kg}(60 \mathrm{lb}): 600,000 \mathrm{U}>27 \mathrm{~kg}(60 \mathrm{lb}): 1.2 \mathrm{M} \mathrm{U}$ & Strong, high \\
\hline \multicolumn{3}{|c|}{ If penicillin-allergic } \\
\hline Cephalexin ${ }^{\mathrm{b}}$ po $\times 10$ days & $20 \mathrm{mg} / \mathrm{kg} /$ dose bid, maximum $500 \mathrm{mg} / \mathrm{dose}$ & Strong, high \\
\hline Cefadroxil $^{\mathrm{b}}$ po $\times 10$ days & $30 \mathrm{mg} / \mathrm{kg}$ once daily, maximum $1 \mathrm{~g}$ & Strong, high \\
\hline Clindamycin po $\times 10$ days & $7 \mathrm{mg} / \mathrm{kg} / \mathrm{dose}$ tid, maximum $300 \mathrm{mg} / \mathrm{dose}$ & Strong, moderate \\
\hline Azithromycin po $\times 5$ days & $\begin{array}{l}12 \mathrm{mg} / \mathrm{kg} \text { once, maximum } 500 \mathrm{mg} \text {, then } 6 \mathrm{mg} / \mathrm{kg} \text { daily, } \\
\text { maximum } 250 \mathrm{mg} \text {, for } 4 \text { days }\end{array}$ & Strong, moderate \\
\hline Clarithromycin po $\times 10$ days & $7.5 \mathrm{mg} / \mathrm{kg} / \mathrm{dose}$ bid, maximum $250 \mathrm{mg} / \mathrm{dose}$ & Strong, moderate \\
\hline
\end{tabular}

American Heart Association, American Academy of Pediatrics (adapted from Shulman et al. 2012).

${ }^{a}$ Strength of recommendation, level of evidence (as detailed in Shulman et al. 2012).

${ }^{\mathrm{b}}$ Avoid with immediate (type I) hypersensitivity to a penicillin.

bid, twice daily; tid, three times daily; po, per os; im, intramuscular.

(once daily), in the absence of immediate-type hypersensitivity to penicillin. Among patients with confirmed amoxicillin hypersensitivity, there is a particular cross-allergenicity with cefadroxil, which, unlike cephalexin, shares an identical $\mathrm{R}$ side chain with amoxicillin (Miranda et al. 1996; Sastre et al. 1996); cephalexin may, therefore, be preferred in this setting. Some investigators provide this initial treatment for 3 weeks, awaiting resolution of neuropsychiatric symptoms.

\section{Treatment of GAS in children with PANS or PANDAS}

With a new diagnosis of PANS, it has been our practice to provide an initial course of antimicrobial treatment for acute streptococcal infection as described earlier, regardless of whether or not GAS is identified at the time of diagnosis, similar to recommendations for the initial management of rheumatic fever (Gerber et al. 2009). Although data from controlled clinical trials are lacking, aggressive diagnosis and treatment of GAS infection seems prudent as a means of mitigating risk for neuronal injury. In practice, the majority of children with recent-onset PANDAS experience a reduction in neuropsychiatric symptoms within days or weeks after antimicrobial treatment active against acute GAS infection (Murphy and Pichichero 2002; Murphy et al. 2004; Snider et al. 2005; Falcini et al. 2013).

A protocol for the suggested management of infection in PANDAS is presented in Table 3.

\section{Secondary antimicrobial prophylaxis for children with PANDAS}

There is currently insufficient evidence to support long-term streptococcal prophylaxis for children with PANDAS. There have been two trials in children with PANDAS. In one trial, Penicillin V $250 \mathrm{mg}$ bid prophylaxis reduced neither GAS infections nor neuropsychiatric symptoms (Garvey et al. 1999). In a second trial, however, penicillin $\mathrm{V}$ or azithromycin given for 1 year reduced the frequency of GAS infections versus the previous year by $95 \%$ and $96 \%$, respectively, with corresponding reductions in neuropsychiatric exacerbations by $75 \%$ and $56 \%$ (Snider et al. 2005).

The potential benefit for secondary antimicrobial prophylaxis in children with well-defined PANDAS lies in the possibility of preventing neural injury from future GAS-associated exacerbations. Prospective evaluations of 50 children in the original PANDAS cohort demonstrated that $77 \%$ of 144 exacerbations were associ- ated with definite or probable GAS (Swedo et al. 1998). A recent follow-up study of PANS patients with or without demonstrable GAS association at onset (Frankovich et al. 2015) identified one or more GAS-associated exacerbations in 14 out of 19 (74\%) cases. These cohorts show that GAS may be temporally associated, if not causally related, to approximately 3 out of 4 of symptom exacerbations in PANDAS patients. Therefore, the prevention of GAS infections may prolong symptom remissions and decrease the number of PANDAS exacerbations.

To this end, members of the Consortium commonly institute long-term streptococcal prophylaxis for the most severely affected children, and for those with multiple GAS-associated neuropsychiatric exacerbations. The rationale for using secondary prophylactic measures is to prevent recurrences of intolerable, debilitating symptoms, as well as to minimize the possible risk of long-term

\section{TABle 3. Management of INFECTION IN PANDAS}

1. Rule out co-existing infectious causes with a thorough history and physical examination, supported by appropriate laboratory testing. A variety of different infections have been proposed to stimulate PANS symptoms, and these should be diagnosed and managed according to standard practices.

2. The provisional guideline in Table 1 may be used to determine the association with GAS infection. Patients with "adequate" evidence for an association with streptococcal infection may be given a provisional diagnosis of PANDAS.

3. For those with PANDAS, an initial course of treatment for GAS is suggested, including re-culture and follow-up management according to "Primary antimicrobial treatment for acute streptococcal infections" and Table 2 given earlier. Continued prophylaxis may then be initiated (see text).

4. For those with documented GAS pharyngitis, a follow-up throat swab 2-7 days after treatment is prudent, as currently recommended for children with rheumatic fever. Re-treatment is recommended if still positive.

5. Ongoing vigilance for streptococcal infection in the patient and all family members is also warranted. With the appearance of suspect symptoms in any family member or other close contact, an early diagnostic study is indicated, followed by prompt treatment for those with documented GAS infection.

PANS, pediatric acute-onset neuropsychiatric syndrome; PANDAS, pediatric autoimmune neuropsychiatric disorder associated with streptococcal infection. 
sequelae or chronic symptoms. Weighing these theoretical benefits against the known risks of long-term antibiotic administration requires a careful consideration of the patient's history and clinical status. We believe that the decision to institute long-term antimicrobial prophylaxis may best be made in consultation with a pediatric infectious diseases specialist, or a member of the PANS/ PANDAS Clinical Research Consortium. When secondary GAS prevention is chosen, the antimicrobial regimens should be based on guidelines developed for the prevention of rheumatic fever (Gerber et al. 2009).

Duration of antimicrobial prophylaxis. A recommendation for the duration of prophylaxis will depend on an emerging experience with late relapses during prolonged follow-up of children and young adults with PANDAS. Anecdotal experiences with late relapses suggest that the preventive regimen should continue for at least a year or two after symptoms have abated. For children in remission, some clinicians optionally suspend antibiotic prophylaxis during the summer months when GAS exposures are expected to be less common. Prophylaxis is resumed in the fall when the child returns to school. If the child remains symptom free during the academic year, antibiotics may be discontinued completely the following summer. Continuing prophylaxis to age 18 in the most severe cases seems reasonable, but should be individualized, based on the frequency and severity of neuropsychiatric exacerbations, time since previous exacerbation, and risk of GAS exposure (e.g., crowded living conditions, younger siblings at home, or GAS outbreaks at school).

\section{Antimicrobial Management Of Nonstreptococcal PANS}

Among PANS patients with no evidence for a GAS initiation, it has been our practice to provide an initial course of antimicrobial treatment as for acute streptococcal infection as described earlier, even though GAS is not identified at the time of diagnosis, because negative studies do not absolutely rule out a hidden source of infection, as described earlier. This is similar to the recommendations for the initial management of rheumatic fever (Gerber et al. 2009). However, in cases without a clear link to GAS infection, long-term antimicrobial prophylaxis is not currently recommended. The risk of symptom exacerbations may be independent of GAS infections and antibiotic prophylaxis would offer no protection against future recurrences. For these patients, close monitoring and early treatment for GAS infection in the patient and family members is advised (Table 4). GAS cultures should be obtained during symptom flares. Positive cultures should be managed as described earlier, under "Primary Antimicrobial Treatment for Streptococcal Infections." Repeated GAS-incited flares would change the diagnosis from non-streptococcal PANS to PANDAS.

\section{Streptococcal IIIness in Contacts of Patients with PANDAS or PANS}

At the time of the first presentation, attention should be given to family history of pharyngitis, impetigo, perianal dermatitis, and other signs and symptoms of GAS infections. If possible, family members should have a throat swab cultured for GAS. Ongoing vigilance against GAS infections in any of the patient's close contacts is important, as symptom exacerbations have been reported after exposure to a sibling with GAS, even when the PANDAS patient had no evidence of frank infection.

For families in which there are unaffected siblings in the 3-12 year age group, prompt medical attention to symptoms that are
Table 4. Management of Nonstreptococcal PanS

1. Although an initial course of antimicrobial treatment is herein recommended for cases, both with and without evidence for streptococcal infection, long-term secondary antibiotic prophylaxis against streptococcal infections is not recommended for patients with non-streptococcal PANS (defined in Table 1). Since the likelihood of a future GAS-induced recrudescence is unclear, the possibility of benefit does not outweigh potential adverse effects of antimicrobial exposure on microbial resistance and on the protective host microbiome.

2. Children with PANS often experience exacerbation of neuropsychiatric symptoms during intercurrent sinusitis or other non-streptococcal infections. These should be promptly evaluated and managed according to current standards of practice.

3. It is possible that GAS may initiate a symptom flare in children with an initial diagnosis of non-streptococcal PANS. It is, therefore, important for families to be vigilant for possible GAS infection in both the patient and close family members.

4. If the PANS patient or close contact has a sore throat, a throat swab should be obtained and treated promptly if GAS is identified.

5. If the PANS patient has a definite increase in PANS symptoms, careful physical evaluation for an inciting infection should be performed. Skin infection, including perianal dermatitis, would warrant appropriate cultures. A throat swab for GAS should be performed even in the absence of clinical pharyngitis. GAS serology (ASO and ADB), and a polymerase chain reaction test for Mycoplasma pneumoniae may be performed as well. A listing of selected laboratory tests for infection is presented in Table 5.

A plan for PANS patients who had negative GAS studies, and are not currently receiving daily antimicrobial prophylaxis.

suggestive of streptococcal infection is important to protect not only the index patient but also the siblings themselves who may be at an increased genetic risk for PANDAS (Dranitzki and Steiner 2007, Lewin et al. 2011; unpublished personal observations).

\section{Infections Other than GAS}

\section{Upper respiratory infections}

The onset and exacerbations of PANS are very frequently associated with common upper respiratory tract infections (Swedo et al. 1998; Murphy et al. 2014; Frankovich et al. 2015). In these reports, the specific causative organism was rarely identified. Acute rhinosinusitis (the common cold), otitis media, and acute or chronic sinusitis are often anecdotally observed with initial onset or exacerbations of PANS. Such infections should be judiciously diagnosed and treated according to standard clinical practice. In the absence of a suggestive clinical syndrome, unfocused broadspectrum serologic diagnostic testing for various microbial pathogens is generally not useful.

Sinusitis is one of the more common infections inciting PANS. Guidelines for the appropriate management of acute and chronic rhinosinusitis should be followed (Slavin et al. 2005; Wald et al. 2013; Hamilos 2016). Although over-diagnosis should be avoided, close attention to those meeting diagnostic criteria for acute or chronic sinusitis is encouraged. When antimicrobial therapy is indicated, amoxicillin-clavulanate is generally preferred for acute sinusitis in children with moderate or severe PANS or PANDAS, 
and for those who have recently been treated with other antibiotics. For frequently recurrent or chronic sinusitis, specialist referral should be considered. Therapies that avoid antimicrobials should be used initially whenever possible.

\section{Influenza}

Influenza has often been documented anecdotally at both initial onset and exacerbations of PANS. Annual influenza immunization is strongly advised for PANS patients and all close contacts. This should be performed according to annual influenza guidelines from the Centers for Disease Control (2016a).

Since influenza is highly contagious, good hand hygiene, proper cough technique, and avoidance of close contact with ill people are appropriate during influenza season. Typical influenza symptoms include abrupt onset of fever, myalgia, malaise, sore throat, and cough. Vigilance for influenza symptoms in patients and family members is prudent during community epidemic periods, with prompt pursuit of appropriate diagnosis and treatment.

Older rapid influenza immunoassays are highly specific but only $50 \%-70 \%$ sensitive, and are, therefore, useful only if positive. Newer rapid and highly sensitive influenza nucleic acid assays are available for swab specimens from the anterior nose (Alere ${ }^{\mathrm{TM}}$ Influenza A\&B assay, Alere-Scarborough, Scarborough, ME) or nasopharynx (Cobas influenza A/B PCR, Roche Molecular Diagnostics, Indianapolis, IN).

The clinical diagnosis and treatment of influenza is considered appropriate without laboratory testing for anyone with compatible symptoms during active community influenza epidemics; current guidelines for diagnosis and treatment should be followed (Centers for Disease Control 2016a). In adults, antiviral treatment with either oral oseltamivir or inhaled zanamivir is most effective within the first 48 hours of illness. However, the initiation of antiviral treatment should not be withheld beyond that 48-hour window for children, who may excrete the virus for longer periods than adults.

\section{Mycoplasma pneumoniae}

M. pneumoniae is a suspected, but not yet proven, trigger of PANS. Most M. pneumoniae infections are indistinguishable from common viral upper respiratory tract infection. Although cough is a common symptom in the acute infection, the characteristic persistent cough syndrome, often presenting sequentially in multiple family members, is less common (American Academy of Pediatrics 2015b). A definitive diagnosis is best made with a M. pneumoniaespecific molecular assay. This assay, which is available through several commercial reference laboratories, may be performed on nasopharyngeal or pharyngeal secretions. A rising IgG titer, which requires acute and convalescent sera, may also be diagnostic (Medjo et al. 2014). M. pneumoniae IgG titers may be elevated for life; a single elevated IgG titer with neither an IgM response nor a positive PCR is not indicative of current infection. Further, the reliability of a single IgM serology has been inconsistent between studies, and it is often prone to false positives (Thurman et al. 2009; Bradley et al. 2011; Medjo et al. 2014). Positive IgM ELISA results should be confirmed by indirect immunofluorescence antibody testing (Smith 1986). However, combined molecular diagnosis and serologic testing together provide the most accurate diagnosis.

$M$. pneumoniae, diagnosed serologically with $\operatorname{IgM}$ antibody and IgG serologic titer rises (Yis 2008) or polymerase chain reaction (Al-Zaidy 2015), has been linked to several neurologic syndromes, including encephalitis, acute disseminated encephalomyelitis, transverse myelitis, peripheral nerve palsy, cerebellar disease, and myasthenia gravis. Among the neurologic syndromes associated with PCR-documented $M$. pneumoniae infection, cases could be separated clinically into active infection and postinfectious syndromes. These occurred, respectively, within 7 days or 7 days or longer after the onset of prodromal respiratory symptoms (Al-Zaidy et al. 2015). Separately, Tourette's syndrome exacerbations have also been linked to $M$. pneumoniae (Müller et al. 2000), and M. pneumoniae antibodies were demonstrated far more commonly in Tourette syndrome patients than in controls (Müller et al. 2004). These findings make it likely that Mycoplasma might also induce PANS, although well-documented cases have yet to be described.

M. pneumoniae pneumonia can be treated with macrolides, azithromycin, or tetracyclines. Macrolide resistance has reached about $10 \%$ in recent years (Diaz et al. 2015), whereas tetracycline resistance remains low.

\section{Lyme borreliosis}

OCD sometimes occurs in patients with Lyme disease (Fallon et al. 1993, 1998; Fallon and Nields 1994). Other PANS-like neuropsychiatric and cognitive symptoms of the post-Lyme disease syndrome include distractibility, poor schoolwork, irritability, depression, insomnia, and sensitivity to light and/or sound (Tager et al. 2001). Oppositional behavior, anxiety disorders, and ADHD are also reported (Fallon et al. 1998). In addition, a case report described a child with Lyme disease who presented with acuteonset Tourette syndrome that resolved with antibiotic treatment (Riedel et al. 1998). However, to date, we are unaware of an unequivocal case of PANS associated with Lyme disease.

A diagnosis of post-Lyme PANS should be restricted to children who: (1) have diagnostic PANS symptoms after an illness compatible with clinical Lyme disease and (2) live in regions where the presence of Lyme disease is established. In the United States, this is almost exclusively limited to the six New England states, New York, New Jersey, Pennsylvania, Maryland, Virginia, Minnesota, and Wisconsin. A few cases are also found in localized areas within North Dakota, Iowa, Indiana, West Virginia, Illinois, and California (Centers for Disease Control and Prevention 2016b). Children outside these regions are unlikely to have a Lyme infection, even if they have a positive laboratory test. Positive Borellia burgdorferi serology is more likely to be falsely positive in these areas. The diagnosis of Lyme disease requires positive screening serology that must be confirmed by Western blot testing, interpreted according to guidelines of the U.S. Centers for Disease Control (Centers for Disease Control and Prevention 2016c).

\section{Other inciting infections and conditions}

A number of additional infections, including gastrointestinal infections, dental infection, herpes simplex, varicella, Epstein-Barr virus, enterovirus, and others, as well as Kawasaki disease and anaphylactoid purpura, have been mentioned in association with the onset or exacerbation of PANS symptoms in a small number of cases (Allen et al. 1995; Swedo et al. 1998; Murphy et al. 2014; Frankovich et al. 2015). Given their number and variety, it seems likely that many apparent infectious triggers may activate symptoms through nonspecific immune activation mechanisms. All intercurrent infections should be considered and managed on an individual basis, according to existing guidelines. In some instances, onset and exacerbations may occur in the absence of any recognizable infection, suggesting that additional disease mechanisms may be involved. 


\section{Assessment of Infection at Initial Onset or During PANS or PANDAS Exacerbations}

Careful consideration of possible inciting infections is important at both the initial onset and symptom exacerbations of PANS or PANDAS. A detailed history of exposures to contagious illnesses should be obtained, with cognizance of their associated incubation periods. Of particular interest are recent exposures to streptococcal pharyngitis or skin infections. Exposure to someone with persistent cough in the previous $1-4$ weeks raises the possibility of M. pneumoniae. Acquisition of any respiratory or febrile illness during periods of community influenza activity strongly suggests that diagnosis, even more so if there was a known close exposure in the previous 2-3 days.

Physical examination should focus on infection at any site, including dental, pharyngeal, lymphatic, and perianal and all other skin sites.

Some options for microbial laboratory diagnosis during onset or an exacerbation are given in Table 5. These include throat or skin site swab for GAS, and serial serum ASO and ADB levels as compared with previous levels if available. Patients receiving

Table 5. Laboratory Assessments of Infection IN CHILDREN WITH PANS

Laboratory tests at first presentation

-Throat swab for GAS rapid test and/or culture

-ASO, ADB; repeat in 2-6 weeks for antibody rise or fall

-Throat or nasopharyngeal swab for M. pneumoniae PCR

$-M$. pneumoniae $\operatorname{IgG}$, $\operatorname{IgM}$ (confirmatory $\operatorname{IgM}$ fluorescent antibody if positive)

-Tests for other infections suspected on the basis of history and physical examination

$-25 \mathrm{OH}$ vitamin D level

-Other medical assessments (immune, autoimmune, etc., tests as noted elsewhere)

-Assess family members and other close contacts

Elective throat swab for GAS

Evaluation for other infections on the basis of history.

Laboratory tests at routine follow-up visits

-Elective throat swab for GAS if not receiving an antimicrobial effective against GAS

-Elective ASO, ADB

-Elective $M$. pneumoniae titers as described earlier

-Elective $25 \mathrm{OH}$ vitamin D level

Laboratory tests during neuropsychiatric symptom exacerbation

-Throat swab for GAS

-Elective ASO, ADB

$-M$. pneumoniae titers as described earlier

-Elective throat or nasopharyngeal $M$. pneumoniae PCR

-Tests for other infections suspected on the basis of history and physical examination

-Elective $25 \mathrm{OH}$ vitamin D level

-Assess family members and other close contacts

Elective throat swab for GAS

Evaluation for other infections on the basis of history.

Laboratory tests to follow up acute GAS infection

-ASO, ADB to diagnose bona fide infection

-Repeat throat swab; re-treat if still positive

Laboratory tests for close contacts with pharyngitis

-Throat swab for GAS rapid test and/or culture; treat if positive

-If GAS was diagnosed and treated, repeat culture 2-7 days after treatment is complete; re-treat if still positive.

PCR, polymerase chain reaction. prophylactic antimicrobials should be included, as a means to identify prophylactic regimen failure. Nasopharyngeal or throat swab may be submitted for M. pneumoniae PCR together with IgG and IgM M. pneumoniae serology. The value of GAS and Mycoplasma serologic studies is enhanced if previous serial antibody levels are available for comparison. Older rapid immune-based assays for influenza antigen are specific but miss about one-third of cases (Chartrand et al. 2012); these assays are useful only if positive. Newer molecular-based tests for influenza nucleic acid mentioned earlier are highly sensitive as well as rapid and specific (see Influenza, above).

\section{Immunizations}

Children with PANS and PANDAS should receive standard childhood vaccines, following recommendations from the Centers for Disease Control and Prevention, the American Academy of Pediatrics, and the American Academy of Family Physicians (Centers for Disease Control and Prevention 2016a). The patient and all family members should receive annual influenza immunization as described under Influenza (described earlier).

We have found that symptom flares after routine childhood immunization, or with pneumococcal polysaccharide vaccine, are relatively uncommon, brief, and manageable with non-steroidal anti-inflammatory agents.

\section{Role of Adenotonsillectomy}

There are no available prospective controlled trials of adenoidectomy and tonsillectomy for PANDAS. Although small case series suggest that improvement may occur after tonsillectomy and/or adenoidectomy (Demesh et al. 2015), a comparative retrospective study found that neither neuropsychiatric symptom severity nor streptococcal antibodies differed among those with prior adenoidectomy and/or tonsillectomy (Murphy et al. 2013). In most cases, the procedure had been performed prior to the PANDAS onset. In a recent prospective study of 120 children with PANDAS, 56 who underwent tonsillectomy and/or adenoidectomy were compared with 64 un-operated controls. During more than a 2-year sequential follow-up, the surgical group did not differ from controls in symptom progression, streptococcal and neuronal antibodies, or severity of neuropsychiatric symptoms (Pavone et al. 2014). We believe that indications for tonsillectomy and/or adenoidectomy should be limited to those recommended for the general population, such as sleepdisordered breathing or frequent GAS infections (Baugh et al. 2011). If surgery is performed, excised tissues should be submitted for GAS culture, since occult tonsil or adenoid GAS infection is common (Saslaw et al. 1962; Gul et al. 2007; Lee et al. 2008).

\section{Role of Probiotics}

There is no clinical evidence that any probiotic affects neuropsychiatric symptomatology. This is an area of ongoing research, however, as there is evidence from animal models and in vitro studies that gut flora may modulate immune reactions and susceptibility to infection (O'Mahony et al. 2015; Ignacio et al. 2016). Such probiotic research is still in its infancy, however, and information is only now emerging to indicate the critical mechanisms involved. At present, however, there is no clinical evidence that any currently available probiotics modulate neuropsychiatric symptoms in children with PANS. Certain probiotics (Saccharomyces boulardii, Lactobacillus rhamnosis) may be used to reduce diarrhea 
that is associated with antimicrobial treatment (Goldenberg et al. 2015).

\section{Vitamin D}

Vitamin D receptors are present in most classes of immune cells. Their action enhances several immune defenses, including potent intracellular microbicidal activity mediated by cathelicidins and LL-37 (Gunville et al. 2013). Many studies have reported an association between low vitamin D levels and increased frequency of various infections (Thornton et al. 2013), including GAS (Nseir et al. 2012) and recurrent tonsillopharyngitis (Yildiz et al. 2012). Prospective studies to demonstrate whether vitamin D prophylaxis can prevent infections are few in number. However, a majority of available pediatric trials demonstrate a reduction in respiratory tract infections (Charan et al. 2012; Ali and McDevitt 2015; Xiao et al. 2015). This includes a study in which influenza was reduced by about half in schoolchildren taking 1200 IU vitamin D3 daily (Urashima et al. 2010). A study of otitis-prone children showed protection from further recurrences when they received $1000 \mathrm{IU}$ vitamin D3 daily (Marchisio et al. 2013). In the latter study, the degree of protection correlated with final serum 25-hydroxy vitamin D levels through a range as high as $40 \mathrm{ng} / \mathrm{mL}$ or more.

In addition to its role in defense against infection, there is also evidence that vitamin D activates immunoregulatory mechanisms with the potential to downregulate autoimmune processes (Peelen et al. 2011; Antico et al. 2012; Rolf et al. 2014). Six of seven treatment trials in various inflammatory conditions showed reductions in inflammatory markers with vitamin D3 treatment, noted particularly when initial vitamin D levels were low (Cannel et al. 2015). Notably, vitamin D3 treatment improved outcomes in patients with multiple sclerosis, another condition of central nervous system autoimmunity (Rotstein et al. 2015).

Taken together, the findings provide indirect evidence to support optimization of Vitamin D levels among children with infectiontriggered neuropsychiatric symptoms. The optimum level of serum 25-hydroxy vitamin D level has not been established. On the basis of this limited evidence, we currently treat PANS patients with vitamin D3 as needed to maintain serum 25-hydroxy vitamin D level above $30 \mathrm{ng} / \mathrm{mL}$ ( $75 \mathrm{nmol} / \mathrm{L}$ ), similar to that recommended by the Endocrine Society (Holick et al. 2011). This can usually be accomplished with a combination of a standard childhood multivitamin plus a vitamin D3 supplement of $1000 \mathrm{U}$ daily for children 5 years of age or less or $2000 \mathrm{U}$ daily for those 6 years or older, doses well within the Institute of Medicine's recommended upper limits for children older than age 1 (Ross et al. 2011). Serum 25-OH vitamin D level may be monitored every 3-12 months, depending on adequacy of levels. It is notable that wintertime, excess body fat, and black, Hispanic, or Asian race are significant risk factors for vitamin D insufficiency (Saggese et al. 2015). Omega-3, fish oils, and cod liver oil may contain substantial amounts of vitamin $\mathrm{D}$; their use can lead to hypervitaminosis.

\section{Conclusion}

This article is designed to provide an initial practical clinical guideline for the management of infections in PANS and its subset, PANDAS. Relationships linking PANS/PANDAS with GAS and other infections are reviewed. Criteria for an operational retrospective diagnosis of GAS infection adequate for the diagnosis of PANDAS are proposed. An initial course of anti-streptococcal treatment for essentially all newly diagnosed cases of PANS is suggested. Chronic secondary antimicrobial prophylaxis of strep- tococcal infections is suggested for children with PANDAS who have severe neuropsychiatric symptoms or recurrent exacerbations associated with GAS infections. For all others, vigilance for GAS infection in both the patient and close contacts is recommended. Since any intercurrent infection may induce a symptom flare, close observation with appropriate therapy for any treatable intercurrent infection is warranted. A guideline for the assessment of infection at initial onset or exacerbations of neuropsychiatric symptoms is provided. Routine childhood immunizations and attention to vitamin D are encouraged. Current data suggesting the limited utility of adenotonsillectomy and probiotics are also presented.

Guidelines provided are supported by data whenever possible, and by the best current judgment of experienced investigators, as indicated in the text. Areas needing further study include the identification of possible specific encephalitogenic strains of streptococci, better serologic tests for the retrospective diagnosis of GAS infections, prospective justification for secondary GAS antimicrobial prophylaxis, and further clarification of the mechanisms of GAS-induced autoimmunity. The clear implication of nonspecific immune activation of symptoms highlights the need to elucidate the common pathways that might be involved. Also needed are a search for additional neuropathologic autoantibodies and molecular mimicries implicating microbial or other antigenic sources, and a clarification of the specific roles of influenza, Mycoplasma, and other infections in this disease. Finally, the safety and utility of the suggested modes of infection prevention require prospective assessment.

\section{Clinical Significance}

The clinical management of children with PANS is often difficult, and scientifically established guidelines are not currently available. This article, from the PANS/PANDAS Research Consortium, is an effort to provide a practical approach to the management of infection components based on current knowledge and the experience of Consortium members. Accompanying papers from the Consortium discuss psychiatric and immunomodulatory management.

\section{Acknowledgment}

The authors acknowledge the support rendered by PANDAS Network, and the Leda J. Sears Trust.

\section{Disclosures}

M.S.C., MD, MPH, None. S.E.S., MD, Employee of National Institute of Mental Health. M.S.P., MD, None. T.K.M., MD, NIH/ NIMH: 1RO1MH093381-01A1, 1R21MH087849-01A1, 1R01HD 080096-01A1, R34; Centers for Disease Control and Prevention: 5U01DD000509-02; International OCD Foundation; AstraZeneca Pharmaceuticals; Sunovion Pharmaceuticals, Inc.; F. HoffmannLaRoche Ltd; PANDAS Network; Neurocrine Biosciences, Inc.; Auspex Pharmaceuticals; Teva Pharmaceuticals; Shire Pharmaceuticals; Pfizer, Inc.; Massachusetts General Hospital; Psyadon Pharmaceuticals, Inc.; Forest Research Institute, Inc.; Tourette Syndrome Association.

\section{References}

Al-Zaidy SA, MacGregor D, Mahant S, Richardson SE, Bitnun A: Neurological complications of PCR-Proven M. pneumoniae Infections in Children: Prodromal illness duration may reflect pathogenetic mechanism. Clin Infect Dis 61:1092-1098, 2015. 
Ali SR, McDevitt H: Question 1: Does vitamin D supplementation prevent acute lower respiratory tract infections in children? Arch Dis Child 100:892-895, 2015.

Allen AJ, Leonard HL, Swedo SE: Case study: A new infectiontriggered, autoimmune subtype of pediatric OCD and Tourette's syndrome. J Am Acad Child Adolesc Psychiatry 34:307-311, 1995.

American Academy of Pediatrics: Group A streptococcal infections. In: Red Book. Report of the Committee on Infectious Diseases, 2015a. Elk Grove Village, IL: American Academy of Pediatrics.

American Academy of Pediatrics: Mycoplasma pneumoniae and other Mycoplasma species infections. In: Red Book. Report of the Committee on Infectious Diseases, 2015b.

Antico A, Tampoia M, Tozzoli R, Bizzaro N. Can supplementation with vitamin $\mathrm{D}$ reduce the risk or modify the course of autoimmune diseases? A systematic review of the literature. Autoimmun Rev 12:127-36, 2012.

Ayoub E, Wannamaker L: Evaluation of the streptococcal desoxyribonuclease $\mathrm{B}$ and diphosphopyridine nucleotidase antibody tests in acute rheumatic fever and acute glomerulonephritis. Pediatrics 29:527-538, 1962.

Baugh RF, Archer SM, Mitchell RB, Rosenfeld RM, Amin R, Burns JJ, Darrow DH, Giordano T, Litman RS, Li KK, Mannix ME, Schwartz RH, Setzen G, Wald ER, Wall E, Sandberg G, Patel MM; American Academy of Otolaryngology-Head and Neck Surgery Foundation: Clinical practice guideline: Tonsillectomy in children. Otolaryngol Head Neck Surg 144:S1-S30, 2011.

Bradley JS, Byington CL, Shah SS, Alverson B, Carter ER, Harrison C, Kaplan SL, Mace SE, McCracken GH Jr, Moore MR, St Peter SD, Stockwell JA, Swanson JT; Pediatric Infectious Diseases Society and the Infectious Diseases Society of America: The management of community-acquired pneumonia in infants and children older than 3 months of age: Clinical practice guidelines by the Pediatric Infectious Diseases Society and the Infectious Diseases Society of America. Clin Infect Dis 53:e25-e76, 2011.

Brimberg L, Benhar I, Mascaro-Blanco A, Alvarez K, Lotan D, Winter C, Klein J, Moses AE, Somnier FE, Leckman JF, Swedo SE, Cunningham MW, Joel D: Behavioral, pharmacological, and immunological abnormalities after streptococcal exposure: A novel rat model of Sydenham chorea and related neuropsychiatric disorders. Neuropsychopharmacology 237:2076-2087, 2012.

Cannell JJ, Grant WB, Holick MF: Vitamin D and inflammation. Dermatoendocrinol 6:e983401, 2015.

Casey JR, Kahn R, Gmoser D, Atlas E, Urbani K, Luber S, Pellman H, Pichichero ME: Frequency of symptomatic relapses of group A beta-hemolytic streptococcal tonsillopharyngitis in children from 4 pediatric practices following penicillin, amoxicillin, and cephalosporin antibiotic treatment. Clin Pediatr (Phila) 47:549-554, 2008.

Centers for Disease Control and Prevention: Seasonal influenza. Information for health professionals. 2016a. https://www.cdc.gov/flu/ professionals/index.htm (Accessed March, 2017).

Centers for Disease Control and Prevention: Lyme disease maps. 2016b. https://www.cdc.gov/lyme/stats/maps.html. (Accessed March, 2017).

Centers for Disease Control and Prevention: Lyme disease: two-Twostep laboratory testing process. 2016c. https://www.cdc.gov/lyme/ diagnosistesting/LabTest/TwoStep/index.html. (Accessed March, 2017).

Chang K, Frankovich J, Cooperstock M, Cunningham MW, Latimer ME, Murphy TK, Pasternack M, Thienemann M, Williams K, Walter J, Swedo SE: Clinical evaluation of youth with pediatric acute-onset neuropsychiatric syndrome (PANS): Recommendations from the 2013 PANS Consensus Conference. PANS Collaborative Consortium. J Child Adolesc Psychopharmacol 25:3-13, 2015.
Charan J, Goyal JP, Saxena D, Yadav P: Vitamin D for prevention of respiratory tract infections: A systematic review and meta-analysis. J Pharmacol Pharmacother 3:300-303, 2012.

Chartrand C, Leeflang MM, Minion J, Brewer T, Pai M: Accuracy of rapid influenza diagnostic tests: A meta-analysis. Ann Intern Med 156:500-511, 2012.

Clegg HW, Giftos PM, Anderson WE, Kaplan EL, Johnson DR: Clinical perineal streptococcal infection in children: Epidemiologic features, low symptomatic recurrence rate after treatment, and risk factors for recurrence. J Pediatrics 167:687-693, 2015.

Cox CJ, Sharma M, Leckman JF, Zuccolo J, Zuccolo A, Kovoor A, Swedo SE, Cunningham MW: Brain human monoclonal autoantibody from Sydenham chorea targets dopaminergic neurons in transgenic mice and signals dopamine D2 receptor: Implications in human disease. J Immunol 191:5524-5541, 2013.

Cox CJ, Zuccolo AJ, Edwards EV, Mascaro-Blanco A, Alvarez K, Stoner J, Chang K, Cunningham MW: Antineuronal antibodies in a heterogeneous group of youth and young adults with tics and obsessive-compulsive disorder. J Child Adolesc Psychopharmacol 25:76-85, 2015.

Cunningham MW, Cox CJ: Autoimmunity against dopamine receptors in neuropsychiatric and movement disorders: A review of Sydenham chorea and beyond. Acta Physiol (Oxf) 216:90-100, 2016.

Danchin MH, Rogers S, Kelpie L, Selvaraj G, Curtis N, Carlin JB, Nolan TM, Carapetis JR: Burden of acute sore throat and group A streptococcal pharyngitis in school-aged children and their families in Australia. Pediatrics 120:950-957, 2007.

Demesh D, Virbalas JM, Bent JP: The role of tonsillectomy in the treatment of pediatric autoimmune neuropsychiatric disorders associated with streptococcal infections (PANDAS). JAMA Otolaryngol Head Neck Surg 141:272-275, 2015.

Diaz MH, Benitez AJ, Winchell JM: Investigations of Mycoplasma pneumoniae infections in the United States: Trends in molecular typing and macrolide resistance from 2006 to 2013. J Clin Microbiol 53:124-130, 2015.

Dileepan T, Smith ED, Knowland D, Hsu M, Platt M, Bittner-Eddy P, Cohen B, Southern P, Latimer E, Harley E, Agalliu D, Cleary PP: Group A Streptococcus intranasal infection promotes CNS infiltration by streptococcal-specific Th17 cells. J Clin Invest 126:303317, 2016.

Dranitzki Z, Steiner I: PANDAS in siblings: A common risk? Eur J Neurol 14:e4, 2007.

Eshel G, Lahat E, Azizi E, Gross B, Aladjem M: Chorea as a manifestation of rheumatic fever-a 30-year survey (1960-1990). Eur J Pediatr 152:645-646, 1993.

Falcini F, Lepri G, Rigante D, Bertini F, Matucci Cerinic M: FPReSFINAL-2252: Descriptive analysis of pediatric autoimmune neuropsychiatric disorder associated with Streptococcus infection (PANDAS) in a cohort of 65 Italian patients. Pediatr Rheumatol 11 (Suppl 2):242, 2013.

Fallon B, Nields J, Parsons B, Liebowitz MR, Klein DF: Psychiatric manifestations of Lyme borreliosis. J Clin Psychiatry 54:263-268, 1993.

Fallon BA, Nields JA: Lyme disease: A neuropsychiatric illness. Am J Psychiatry 151:1571-1583, 1994.

Fallon BA, Kochevar JM, Gaito A, Nields JA: The underdiagnosis of neuropsychiatric Lyme disease in children and adults. Psychiatr Clin North Am 21:693-703, 1998.

Frankovich J, Thienemann M, Pearlstein J, Crable A, Brown K, Chang $\mathrm{K}$ : Multidisciplinary clinic dedicated to treating youth with pediatric acute-onset neuropsychiatric syndrome: Presenting characteristics of the first 47 consecutive patients. J Child Adolesc Psychopharmacol 25:38-47, 2015. 
Frankovich J, Swedo S, Murphy T, Dale RC, Agalliu D, Williams K, Daines M, Hornig M, Chugani H, Sanger T, Muscal E, Pasternack M, Cooperstock M, Gans H, Zhang Y, Cunningham M, Bernstein G, Bromberg R, Willett T, Brown K, Farhadian B, Chang K, Geller D, Hernandez J, Sherr J, Shaw R, Latimer E, Leckman J, Thienemann M: Clinical management of pediatric acute-onset neuropsychiatric syndrome (PANS): Part II-Use of immunomodulatory therapies. J Child Adolesc Psychopharm 2017 [E-pub ahead of print] DOI: 10.1089/cap.2016.0148.

Garvey MA, Perlmutter SJ, Allen AJ, Hamburger S, Lougee L, Leonard HL, Witowski ME, Dubbert B, Swedo SE: A pilot study of penicillin prophylaxis for neuropsychiatric exacerbations triggered by streptococcal infections. Biol Psychiatry 45:1564-1571, 1999.

Gerber MA, Baltimore RS, Eaton CB, Gewitz M, Rowley AH, Shulman ST, Taubert KA: Prevention of rheumatic fever and diagnosis and treatment of acute streptococcal pharyngitis. Circulation 119:1541-1551, 2009.

Goldenberg JZ, Lytvyn L, Steurich J, Parkin P, Mahant S, Johnston BC: Probiotics for the prevention of pediatric antibiotic-associated diarrhea. Cochrane Database Syst Rev 22:12, 2015.

Gul M, Okur E, Ciragil P, Yildirim I, Aral M, Akif Kilic M: The comparison of tonsillar surface and core cultures in recurrent tonsillitis. Am J Otolaryngol 28:17317-17326, 2007.

Gunville CF, Mourani PM, Ginde AA: The role of vitamin D in prevention and treatment of infection. Inflamm Allergy Drug Targets 12:239-245, 2013.

Hamilos DL: Chronic rhinosinusitis: Management. In: UpToDate. Edited by Post, TW. Waltham, MA, UpToDate, 2016.

Hoffman KL, Hornig M, Yaddanapudi K, Jabado O, Lipkin WI: A murine model for neuropsychiatric disorders associated with group A beta-hemolytic streptococcal infection. J Neurosci 24:17801791, 2004.

Holick MF, Binkley NC, Bischoff-Ferrari HA, Gordon CM, Hanley DA, Heaney RP, Murad MH, Weaver CM; Endocrine Society: Evaluation, treatment, and prevention of vitamin D deficiency: An endocrine society clinical practice guideline. J Clin Endocrinol Metab 96:1911-1930, 2011.

Ignacio A, Morales CI, Câmara NO, Almeida RR: Innate sensing of the gut microbiota: Modulation of inflammatory and autoimmune diseases. Front Immunol 7:54-65, 2016.

Johnson DR, Kurlan R, Leckman J, Kaplan EL: The human immune response to streptococcal extracellular antigens: Clinical, diagnostic, and potential pathogenetic implications. Clin Infect Dis 50:481490, 2010.

Kaplan E, Ferrieri P, Wannamaker L: Comparison of the antibody response to streptococcal cellular and extracellular antigens in acute pharyngitis. J Pediatr 84:21-28, 1974.

Kaplan EL, Huew BB: The sensitivity and specificity of an agglutination test for antibodies to streptococcal extracellular antigens: A quantitative analysis and comparison of the Streptozyme test with the anti-streptolysin $\mathrm{O}$ and anti-deoxyribonuclease B tests. J Pediatr 96:367-373, 1980.

Kaplan EL, Rothermel CD, Johnson DR: Antistreptolysin O and antideoxyribonuclease B titers: Normal values for children ages 2 to 12 in the United States. Pediatrics 101:86-88, 1998.

Kaplan EL, Top FH Jr, Dudding BA, Wannamaker LW: Diagnosis of streptococcal pharyngitis: Differentiation of active infection from the carrier state in the symptomatic child. J Infect Dis 123:490-501, 1971.

Kirvan CA, Swedo SE, Heuser JS, Cunningham MW: Mimicry and autoantibody-mediated neuronal cell signaling in Sydenham chorea. Nat Med 9:914-920, 2003.

Kirvan CA, Swedo SE, Kurahara D, Cunningham MW: Streptococcal mimicry and antibody-mediated cell signaling in the pathogenesis of Sydenham's chorea. Autoimmunity 39:21-29, 2006a.
Kirvan CA, Swedo SE, Snider LA, Cunningham MW: Antibody mediated neuronal cell signaling in behavior and movement disorders. J Neuroimmunol 179:173-179, 2006b.

Kirvan CA, Cox CJ, Swedo SE, Cunningham MW: Tubulin is a neuronal target of autoantibodies in Sydenham's chorea. J Immunol 178:7412-7421, 2007.

Kronman MP, Zhou C, Mangione-Smith R: Bacterial prevalence and antimicrobial prescribing trends for acute respiratory tract infections. Pediatrics 134:e956-e965, 2014.

Kurlan R, Johnson D, Kaplan EL; Tourette Syndrome Study Group: Streptococcal infection and exacerbations of childhood tics and obsessive-compulsive symptoms: A prospective blinded cohort study. Pediatrics 121:1188-1197, 2008.

Lean WL, Arnup S, Danchin M, Steer AC: Rapid diagnostic tests for group A streptococcal pharyngitis: A meta-analysis. Pediatrics 134:771-781, 2014.

Leckman JF, King RA, Gilbert DL, Coffey BJ, Singer HS, Dure LS 4th, Grantz H, Katsovich L, Lin H, Lombroso PJ, Kawikova I, Johnson DR, Kurlan RM, Kaplan EL: Streptococcal upper respiratory tract infections and exacerbations of tic and obsessivecompulsive symptoms: A prospective longitudinal study. J Am Acad Child Adolesc Psychiatry 50:108-118, 2011.

Lee JH, Uhl JR, Cockerill FR 3rd, Weaver AL, Orvidas LJ: Real-time PCR vs standard culture detection of group A beta-hemolytic streptococci at various anatomic sites in tonsillectomy patients. Arch Otolaryngol Head Neck Surg 134:1177-1181, 2008.

Leslie DL, Kozma L, Martin A, Landeros A, Katsovich L, King RA, Leckman JF: Neuropsychiatric disorders associated with streptococcal infection: A case-control study among privately insured children. J Am Acad Child Adolesc Psychiatry 47:1166-1172, 2008.

Lewin AB, Storch EA, Murphy TK: Pediatric autoimmune neuropsychiatric disorders associated with Streptococcus in identical siblings. J Child Adolesc Psychopharmacol 21:177-182, 2011.

Lin H, Williams KA, Katsovich L, Findley DB, Grantz H, Lombroso PJ, King RA, Bessen DE, Johnson D, Kaplan EL, LanderosWeisenberger A, Zhang H, Leckman JF: Streptococcal upper respiratory tract infections and psychosocial stress predict future tic and obsessive-compulsive symptom severity in children and adolescents with Tourette syndrome and obsessive-compulsive disorder. Biol Psychiatry 67:684-691, 2010.

Logan LK, McAuley JB, Shulman ST: Macrolide treatment failure in streptococcal pharyngitis resulting in acute rheumatic fever. Pediatrics 129:e798-e802, 2012.

Lotan D, Benhar I, Alvarez K, Mascaro-Blanco A, Brimberg L, Frenkel D, Cunningham MW, Joel D: Behavioral and neural effects of intra-striatal infusion of anti-streptococcal antibodies in rats. Brain Behav Immun 38:249-262, 2014.

Luo F, Leckman JF, Katsovich L, Findley D, Grantz H, Tucker DM, Lombroso PJ, King RA, Bessen DE: Prospective longitudinal study of children with tic disorders and/or obsessive-compulsive disorder: Relationship of symptom exacerbations to newly acquired streptococcal infections. Pediatrics 113:e578-e585, 2004.

Marchisio P, Consonni D, Baggi E, Zampiero A, Bianchini S, Terranova L, Tirelli S, Esposito S, Principi N: Vitamin D supplementation reduces the risk of acute otitis media in otitis-prone children. Pediatr Infect Dis J 32:1055-1060, 2013.

Martino D, Chiarotti F, Buttiglione M, Cardona F, Creti R, Nardocci N, Orefici G, Veneselli E, Rizzo R; Italian Tourette Syndrome Study Group: The relationship between group A streptococcal infections and Tourette syndrome: A study on a large service-based cohort. Dev Med Child Neurol 53:951-957, 2011.

McCarty M: The antibody response to streptococcal infections. In: Streptococcal Infections. Edited by McCarty M. New York: Columbia University Press, 1954, pp. 130-142. 
Medjo B, Atanaskovic-Markovic M, Radic S, Nikolic D, Lukac M, Djukic S: Mycoplasma pneumoniae as a causative agent of community-acquired pneumonia in children: Clinical features and laboratory diagnosis. Ital J Pediatr 40:104, 2014.

Mell LK, Davis RL, Owens D: Association between streptococcal infection and obsessive-compulsive disorder, Tourette's syndrome, and tic disorder. Pediatrics 116:56-60, 2005.

Miranda A, Blanca M, Vega JM, Moreno F, Carmona MJ, García JJ, Segurado E, Justicia JL, Juarez C: Cross-reactivity between a penicillin and a cephalosporin with the same side chain. J Allergy Clin Immunol 98:671-677, 1996.

Müller N, Riedel M, Blendinger C, Oberle K, Jacobs E, Abele-Horn M: Childhood Tourette's syndrome and infection with Mycoplasma pneumoniae. Am J Psychiatry 157:481-482, 2000.

Müller N, Riedel M, Blendinger C, Oberle K, Jacobs E, Abele-Horn M: Mycoplasma pneumoniae infection and Tourette's syndrome. Psychiatry Res 129:119-125, 2004.

Murphy ML, Pichichero M: Prospective identification and treatment of children with pediatric autoimmune neuropsychiatric disorder associated with group A streptococcal infection (PANDAS). Arch Pediatr Adolesc Med 156:356-361, 2002.

Murphy TK, Sajid M, Soto O, Shapira N, Edge P, Yang M, Lewis MH, Goodman WK: Detecting pediatric autoimmune neuropsychiatric disorders associated with Streptococcus in children with obsessive-compulsive disorder and tics. Biol Psychiatry 55:61-68, 2004.

Murphy TK, Snider LA, Mutch PJ, Harden E, Zaytoun A, Edge PJ, Storch EA, Yang MC, Mann G, Goodman WK, Swedo SE: Relationship of movements and behaviors to Group A Streptococcus infections in elementary school children. Biol Psychiatry 61:279284, 2007.

Murphy TK, Eric A, Storch EA, Lewin AB, Edge PJ, Goodman WK: Clinical factors associated with PANDAS. J Pediatr 160:314-319, 2012.

Murphy TK, Lewin AB, Parker-Athill EC, Storch EA, Mutch PJ: Tonsillectomies and adenoidectomies do not prevent the onset of pediatric autoimmune neuropsychiatric disorder associated with group A Streptococcus. Pediatr Infect Dis J 32:834-838, 2013.

Murphy TK, Gerardi DM, Leckman JF: Pediatric acute-onset neuropsychiatric syndrome. Psychiatr Clin N Am 37:353-374, 2014.

Murphy TK, Parker-Athill EC, Lewin AB, Storch EA, Mutch PJ: Cefdinir for recent-onset pediatric neuropsychiatric disorders: A pilot randomized trial. J Child Adolesc Psychopharmacol 25:57-64, 2015.

Murphy TK, Patel PD, McGuire JF, Kennel A, Mutch PJ, ParkerAthill EC, Hanks CE, Lewin AB, Storch EA, Toufexis MD, Dadlani GH, Rodriguez CA: Characterization of the pediatric acute-onset neuropsychiatric syndrome phenotype. J Child Adolesc Psychopharmacol 25:14-25, 2015.

Nseir W, Mograbi J, Abu-Rahmeh Z, Mahamid M, Abu-Elheja O, Shalata A: The association between vitamin $D$ levels and recurrent group A streptococcal tonsillopharyngitis in adults. Int J Infect Dis 16:e735-e738, 2012.

O’Dwyer K, Hackel M, Hightower S, Hoban D, Bouchillon S, Qin D, Aubart K, Zalacain M, Butler D: Comparative analysis of the antibacterial activity of a novel peptide deformylase inhibitor, GSK1322322. Antimicrob Agents Chemother 57:2333-2342, 2013.

O' Mahony SM, Stilling RM, Dinan TG, Cryan JF: The microbiome and childhood diseases: Focus on brain-gut axis. Birth Defects Res C Embryo Today 105:296-313, 2015.

Obregon D, Parker-Athill EC, Tan J, Murphy T: Psychotropic effects of antimicrobials and immune modulation by psychotropics: Implications for neuroimmune disorders. Neuropsychiatry (London) 2:331-343, 2012.
Pavone P, Rapisarda V, Serra A, Nicita F, Spalice A, Parano E, Rizzo R, Maiolino L, Di Mauro P, Vitaliti G, Coco A, Falsaperla A, Trifiletti RR, Cocuzza S: Pediatric autoimmune neuropsychiatric disorder associated with group a streptococcal infection: The role of surgical treatment. Int J Immunopathol Pharmacol 27:371-378, 2014.

Peelen E, Knippenberg S, Muris AH, Thewissen M, Smolders J, Tervaert JW, Hupperts R, Damoiseaux J: Effects of vitamin D on the peripheral adaptive immune system: A review. Autoimmun Rev 10:733-743, 2011.

Perrin EM, Murphy ML, Casey JR, Pichichero ME, Runyan DK, Miller WC, Snider LA, Swedo SE: Does group A beta-hemolytic streptococcal infection increase risk for behavioral and neuropsychiatric symptoms in children? Arch Pediatr Adolesc Med 158: 848-856, 2004.

Riedel M, Straube A, Schwarz MJ, Wilske B, Müller N: Lyme disease presenting as Tourette's syndrome. Lancet 351:418-419, 1998.

Rolf L, Muris AH, Hupperts R, Damoiseaux J: Vitamin D effects on B cell function in autoimmunity. Ann N Y Acad Sci 1317:84-91, 2014.

Ross CA, Taylor CL, Yaktine AL, Del Valle HB (eds). Dietary Reference Intakes for Calcium and Vitamin D. Institute of Medicine (US) Committee to Review Dietary Reference Intakes for Vitamin D and Calcium. Washington (DC): National Academies Press, 2011.

Rotstein DL, Healy BC, Malik MT, Carruthers RL, Musallam AJ, Kivisakk P, Weiner HL, Glanz B, Chitnis T: Effect of vitamin D on MS activity by disease-modifying therapy class. Neurol Neuroimmunol Neuroinflamm 2:e167, 2015.

Saggese G, Vierucci F, Boot AM, Czech-Kowalska J, Weber G, Camargo CA Jr, Mallet E, Fanos M, Shaw NJ, Holick MF: Vitamin D in childhood and adolescence: An expert position statement. Eur J Pediatr 174:565-576, 2015.

Saslaw MS, Jablon JM, Jenks SA, Branch CC: $\beta$-hemolytic streptococci in tonsillar tissue. The efficacy of penicillin. Am J Dis Child 103:19-26, 1962.

Sastre J, Quijano LD, Novalbos A, Hernandez G, Cuesta J, de las Heras M, Lluch M, Fernandez M: Clinical cross-reactivity between amoxicillin and cephadroxil in patients allergic to amoxicillin and with good tolerance of penicillin. Allergy 51:383-386, 1996.

Shaikh N, Leonard E, Martin JM: Prevalence of streptococcal pharyngitis and streptococcal carriage in children: A meta-analysis. Pediatrics 126:e557-e564, 2010.

Shaikh N, Swaminathan N, Hooper EG: Accuracy and precision of the signs and symptoms of streptococcal pharyngitis in children: A systematic review. J Pediat 160:487-493, 2012.

Shulman ST, Bisno AL, Clegg HW, Gerber MA, Kaplan EL, Lee G, Martin JM, Van Beneden C: Clinical practice guideline for the diagnosis and management of group A streptococcal pharyngitis: 2012 update by the Infectious Diseases Society of America. Clin Infect Dis 55:1279-1282, 2012.

Silva-Costa C, Friães A, Ramirez M, Melo-Cristino J: Macrolideresistant Streptococcus pyogenes: Prevalence and treatment strategies. Expert Rev Anti Infect Ther 13:615-628, 2015.

Slavin RG, Spector SL, Bernstein IL, Kaliner MA, Kennedy DW, Virant FS, Wald ER, Khan DA, Blessing-Moore J, Lang DM, Nicklas RA, Oppenheimer JJ, Portnoy JM, Schuller DE, Tilles SA, Borish L, Nathan RA, Smart BA, Vandewalker ML; American Academy of Allergy, Asthma and Immunology; American College of Allergy, Asthma and Immunology; Joint Council of Allergy, Asthma and Immunology. The diagnosis and management of sinusitis: A practice parameter update. J Allergy Clin Immunol $116(6$ Suppl):S13-S47, 2005.

Smit PW, Lindholm L, Lyytikäinen O, Jalava J, Pätäri-Sampo A, Vuopio J: Epidemiology and emm types of invasive group A streptococcal infections in Finland, 2008-2013. Eur J Clin Microbiol Infect Dis 34:2131-2136, 2015. 
Smith T: Mycoplasma pneumoniae infections: Diagnosis based on immunofluorescence titer of $\operatorname{IgG}$ and IgM antibodies. Mayo Clin Proc 61:830-831, 1986.

Snider LA, Lougee L, Slattery M, Grant P, Swedo SE: Antibiotic prophylaxis with azithromycin or penicillin for childhood-onset neuropsychiatric disorders. Biol Psychiatry 57:788-792, 2005.

Swedo SE, Leonard HL, Garvey M, Mittleman B, Allen AJ, Perlmutter S, Lougee L, Dow S, Zamkoff J, Dubbert BK: Pediatric autoimmune neuropsychiatric disorders associated with streptococcal infections: Clinical description of the first 50 cases. Am J Psychiatry 155:264-271, 1998.

Swedo SE, Leckman JF, Rose NR: From Research Subgroup to Clinical Syndrome: Modifying the PANDAS Criteria to Describe PANS (Pediatric Acute-onset Neuropsychiatric Syndrome). Pediatr Therapeut 2:113-121, 2012.

Tager FA, Fallon BA, Keilp J, Rissenberg M, Jones CR, Liebowitz MR: A controlled study of cognitive deficits in children with chronic Lyme disease. J Neuropsychiatry Clin Neurosci 13:500-507, 2001.

Thienemann M, Murphy T, Leckman J, Shaw R, Williams K, MD, Kapphahn C, Frankovich J, Geller D, Bernstein G, Chang K, Elia J, Hommer R, Swedo SE: Clinical management of Pediatric Acuteonset Neuropsychiatric Syndrome (PANS): Part I-psychiatric and behavioral interventions. J Child Adolesc Psychopharm 2017 [Epub ahead of print]; DOI: 10.1089/cap.2016.0145.

Thornton KA, Marín C, Mora-Plazas M, Villamor E: Vitamin D deficiency associated with increased incidence of gastrointestinal and ear infections in school-age children. Pediatr Infect Dis J 32:585593, 2013.

Thurman KA, Walter ND, Schwartz SB, Mitchell SL, Dillon MT, Baughman AL, Deutscher M, Fulton JP, Tongren JE, Hicks LA, Winchell JM: Comparison of laboratory diagnostic procedures for detection of Mycoplasma pneumoniae in community outbreaks. Clin Infect Dis 48:1244-1249, 2009.

Toufexis MD, DeOleo C, Elia J, Murphy TK: A link between perianal strep and pediatric autoimmune neuropsychiatric disorder associated with streptococcal infection (PANDAS). J Neuropsychiatry Clin Neurosci 26:164-168, 2014.

Urashima M, Segawa T, Okazaki M, Kurihara M, Wada Y, Ida H: Randomized trial of vitamin D supplementation to prevent seasonal influenza A in schoolchildren. Am J Clin Nutr 91:1255-1260, 2010.
Villaseñor-Sierra A, Katahira E, Jaramillo-Valdivia AN, BarajasGarcía Mde L, Bryant A, Morfín-Otero R, Márquez-Díaz F, Tinoco JC, Sánchez-Corona J, Stevens DL: Phenotypes and genotypes of erythromycin-resistant Streptococcus pyogenes strains isolated from invasive and non-invasive infections from Mexico and the USA during 1999-2010. Int J Infect Dis 16:e178-e181, 2012.

Wald ER, Applegate KE, Bordley C, Darrow DH, Glode MP, Marcy SM, Nelson CE, Rosenfeld RM, Shaikh N, Smith MJ, Williams PV, Weinberg ST; American Academy of Pediatrics: Clinical practice guideline for the diagnosis and management of acute bacterial sinusitis in children aged 1 to 18 years. Pediatrics 132:e262-e280, 2013.

Wannamaker LW, Ayoub EM: Antibody titers in acute rheumatic fever. Circulation 21:598-614, 1960.

Xiao L, Xing C, Yang Z, Xu S, Wang M, Du H, Liu K: Huang Z: Vitamin D supplementation for the prevention of childhood acute respiratory infections: A systematic review of randomised controlled trials. Br J Nutr 114:1026-1034, 2015.

Yaddanapudi K, Hornig M, Serge R, De Miranda J, Baghban A, Villar G, Lipkin WI: Passive transfer of Streptococcus-induced antibodies reproduces behavioral disturbances in a mouse model of pediatric autoimmune neuropsychiatric disorders associated with streptococcal infection. Mol Psychiatry 15:712-726, 2010.

Yildiz I, Unuvar E, Zeybek U, Toptas B, Cacina C, Toprak S, Kilic A, Aydin S: The role of vitamin D in children with recurrent tonsillopharyngitis. Ital J Pediatr 38:25-31, 2012.

Zaura E, Brandt BW, Teixeira de Mattos MJ, Buijs MJ, Caspers MPM, Rashid MU, Weintraub A, Nord CE, Savell A, Hu Y, Coates AR, Hubank M, Spratt DA, Wilson M, Keijser BJF, Crielaard W: Same exposure but two radically different responses to antibiotics: Resilience of the salivary microbiome versus long-term microbial shifts in feces. mBio 6:e01693-e1715, 2015.

Address correspondence to: Michael Cooperstock, MD, MPH Women's and Children's Hospital 400 N. Keene Street Columbia, MO 65201

E-mail: cooperstockm@missouri.edu 